\title{
PERANCANGAN APLIKASI PENDAFTARAN SERVICE MOTOR DAN PENJUALAN SPARE PART PADA BENGKEL JALI
}

\author{
Fajar Trisnadi \\ Program Studi Informatika, Fakultas Teknik dan Ilmu Komputer, Universitas Indraprasta PGRI \\ Jalan Raya Tengah No 80, Kelurahan Gedong, Pasar Rebo, Jakarta Timur \\ Fajar.trisnadi@gmail.com
}

\begin{abstract}
Abstrak
Bengkel Jali motor dalam melakukan pelayanan konsumen selama ini masih menemui kesulitan dan kesalahan. Hal itu disebabkan dalam melakukan transaksi yang dilakukan oleh Pihak Bengkel Jali Motor masih menggunakan cara manual. Mengingat hal tersebut dapat mengakibatkan kesalahan-kesalahan dalam pencatatan data hingga pembuatan laporan. Maka tujuan dari penelitian ini adalah untuk merancang aplikasi pendaftaran service motor dan penjualan sparepart. Metode penelitian yang digunakan dalam penelitian ini menggunakan metode grounded research yaitu suatu metode penelitian berdasarkan pada fakta dan menggunakan analisis perbandingan dengan tujuan mengadakan generalisasi empiris, menetapkan konsep, membuktikan teori, mengembangkan teori, pengumpulan dan analisis data dalam waktu yang bersamaan. Hasil dari penelitian ini adalah aplikasi yang dapat memberikan kemudahan terutama dalam mendapatkan informasi yang berkenaan dengan kegiatann pendaftaran service dan penjualan spare part pada bengkel jali motor.
\end{abstract}

Kata Kunci : Aplikasi Penjualan dan Service Motor, Spare Part, Java

\begin{abstract}
Abstact
Jali motor repair shop in conducting customer service so far is still waiting for difficulties and mistakes. Things that cause transactions conducted by the Jali Motor Workshop still use the manual method. Given this can cause errors in recording data to making reports. Then the purpose of this research is to register motorbike service registration and spare part sales. The research method used in this study uses the method of grounded research which is a method of research based on facts and uses an analysis of the objectives held empirical generalizations, formulating concepts, proving theories, developing theories, collecting and analyzing data in the time taken. The results of this study are applications that can give priority to getting information relating to service registration and spare parts sales activities at a motorbike repair shop.
\end{abstract}

Keywords : Application Sales and Service Motor, Spare Part, Java

\section{PENDAHULUAN}

Bengkel Jali Motor adalah sebuah usaha yang bergerak dalam bidang pelayanan jasa dan penjualan suku cadang kendaran roda dua. Dalam kegiatannya, Bengkel Jali Motor menerima dan memenuhi permintaan pelayanan service kendaraan dan spare part dari pelanggan. Pelayanan adalah suatu kegiatan atau urutan kegiatan yang terjadi dalam interaksi langsung antar seseorang dengan orang lain atau mesin secara fisik, dan menyediakan kepuasan pelanggan tertentu (Sinambela, 2011). Semua kegiatan pelayanan Bengkel meliputi pendataan pelanggan, penggantian spare part, pengantaran spare part sampai dengan pembuatan laporan masih dilakukan dengan cara manual yaitu dicatat menggunakan sebuah buku. Tentunya hal tersebut dapat menimbulkan berbagai kendala misalnya dari segi efisiensi waktu, secara tidak langsung dapat mengurangi kecepatan dan ketepatan khususnya pada saat pengecekan persediaan atau stok spare part. Selain itu pengelola bengkel juga mengalami kesulitan untuk memberikan rekomendasi waktu yang digunakan untuk service berkala kepada pelanggan agar melakukan service tepat waktu, sehingga terkadang meyebabkan kendaran pelanggan sudah melampaui batas waktu standar service berkala yang dianjurkan. Kendala lainnya adalah tidak adanya backup data, sehingga jika buku tersebut hilang atau rusak maka hilang semua data-data tersebut. Tentu saja hal tersebut akan merugikan bagi pihak Bengkel.

Oleh karena itu di butuhkan sebuah sistem yang dapat mendukung semua kegiatan yang dilakukan oleh Begkel Jali Motor agar menjadi lebih mudah khususnya dalam penjualan spare part dan service kendaraan. Sistem adalah kumpulan dari elemen-elemen yang berinteraksi untuk mencapai suatu tujuan tertentu (Jogiyanto, 2005). Tujuan dari penelitian ini adalah merancang sistem yang masih manual agar terkomputerisasi dengan baik sehingga dapat mempermudah pihak Bengkel dalam 
mengolah data, pencarian data, meminimalisir terjadi redudansi data, mempermudah transaksi service, serta membuat laporan yang lebih efektif dan efisien dengan menggunakan Bahasa pemrograman JAVA dengan MySQL sebagai databasenya. Manfaat dari penelitian ini adalah aplikasi yang dibuat diharapkan dapat memberikan kemudahan dalam menyampaikan informasi berkenaan dengan kegiatan informasi, berkenaan dengan kegiatan penjualan spare part dan service pada bengkel jali motor serta dapat menambah pengetahuan bagi pembaca yang bisa di gunakan untuk sumber informasi bagi penelitian lebih lanjut dengan pokok persoalan yang menyangkut dengan sistem jasa penjualan spare part dan service kendaraan.

\section{PENELITIAN RELEVAN}

Penelitian oleh Cicilia Rasmawati (2012) dalam penelitian yang berjudul "Aplikasi Penjualan Batako Pada Perusahan Batako Kurnia Blok". Tujuan dari penelitian ini adalah merancang aplikasi yang dapat memudahkan perusahaan dalam mengelola data penjualan batako (Rismawati, 2012).

Penelitian oleh Rifal Surya Erlangga (2013) dalam penelitian yang berjudul "Sistem Informasi Pelayanan Jasa service dan Penjualan SparePart Motor Berbasis Dekstop Pada Bengkel Merdeka Abadi Motor Bandung" Hasil dari penelitian ini adalah Sistem Informasi Pelayanan Jasa Service Dan Penjualan Sparepart Pada Bengkel Merdeka Abadi Motor yang diharapkan dalam pengolahan data service dan pembuatan laporan penjualan di Bengkel menjadi terkomputerisasi dengan baik (Erlangga, 2013).

\section{METODE PENELITIAN}

Metode penelitian yang digunakan oleh peneliti adalah metode grounded. Metode grounded yaitu suatu metode penelitian berdasarkan pada fakta dan menggunakan analisis perbandingan dengan tujuan mengadakan generalisasi empiris, menetapkan konsep, membuktikan teori, mengembangkan teori, pengumpulan dan analisis data dalam waktu yang bersamaan (Barnabas, 2018). Dalam riset ini data merupakan sumber teori atau teori berdasarkan data.

\section{Metode pengumpulan data}

Metode pengumpulan data yang digunakan sebagai berikut :

1. Metode Observasi, dengan cara mengadakan kunjungan langsung kelapangan dimana dapat secara langsung mencatat hal-hal yang dirasa penting dan sesuai dengan masalah yang akan diambil. Untuk metode ini dilakukan dengan bimbingan dari perusahaan.

2. Metode Wawancara, dengan cara mengajukan beberapa pertanyaan secara langsung kepada karyawan.

3. Metode Dokumentasi, pengumpulan data dengan mengutip dari buku-buku acuan yang diberikan perusahaan maupun yang didapat dari buku-buku teknik yang berasal dari sumber-sumber.

\section{HASIL PENELITIAN \\ Perancangan Antar Muka}

Perancangan antar muka adalah sebuah rancangan bentuk pada tampilan yang dapat dilihat pada sebuah program aplikasi komputer. Komponen antar muka bertujuan untuk memenuhi salah satu kriteria interaksi antara manusia dan komputer yakni agar mendapat perhatian pengguna kepada program aplikasi yang dibuat. Berikut perancangan input dan output yang dijadikan acuan oleh pemakai (user) dalam menjalankan program yang telah dibuat. 


\section{Tampilan Login}

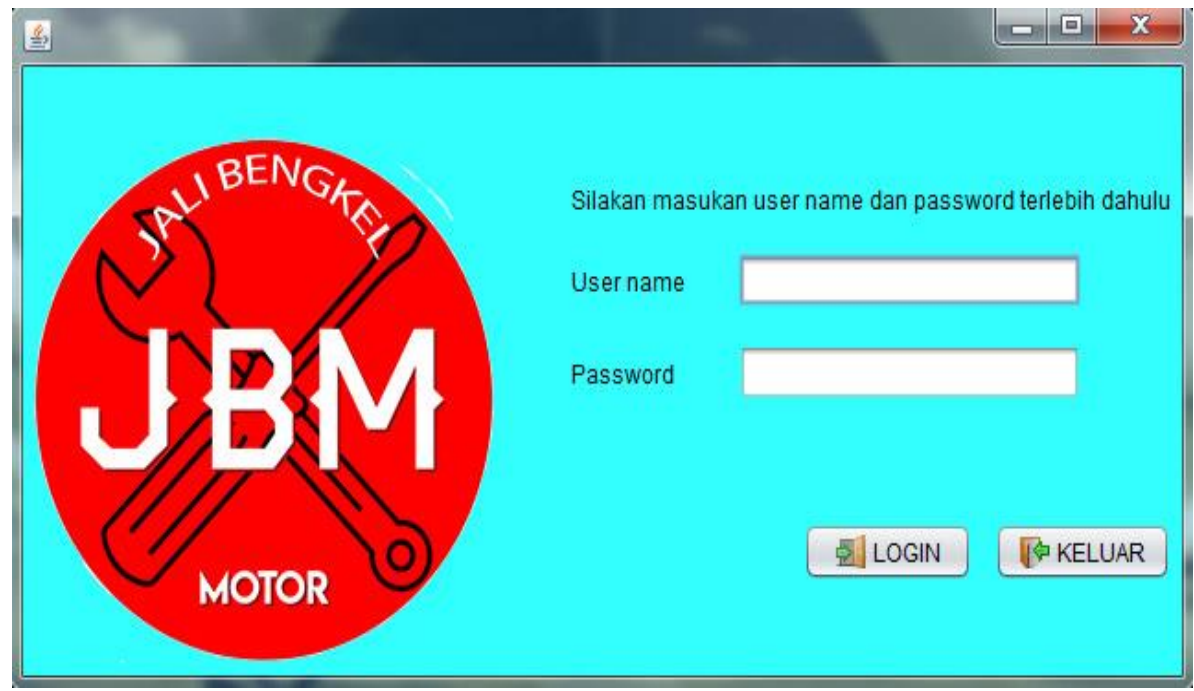

Gambar 1. Tampilan Login

Halaman Login berguna untuk masuk kedalam system sesuai dengan username dan password masing-masing account.

\section{Tampilan Menu Utama}

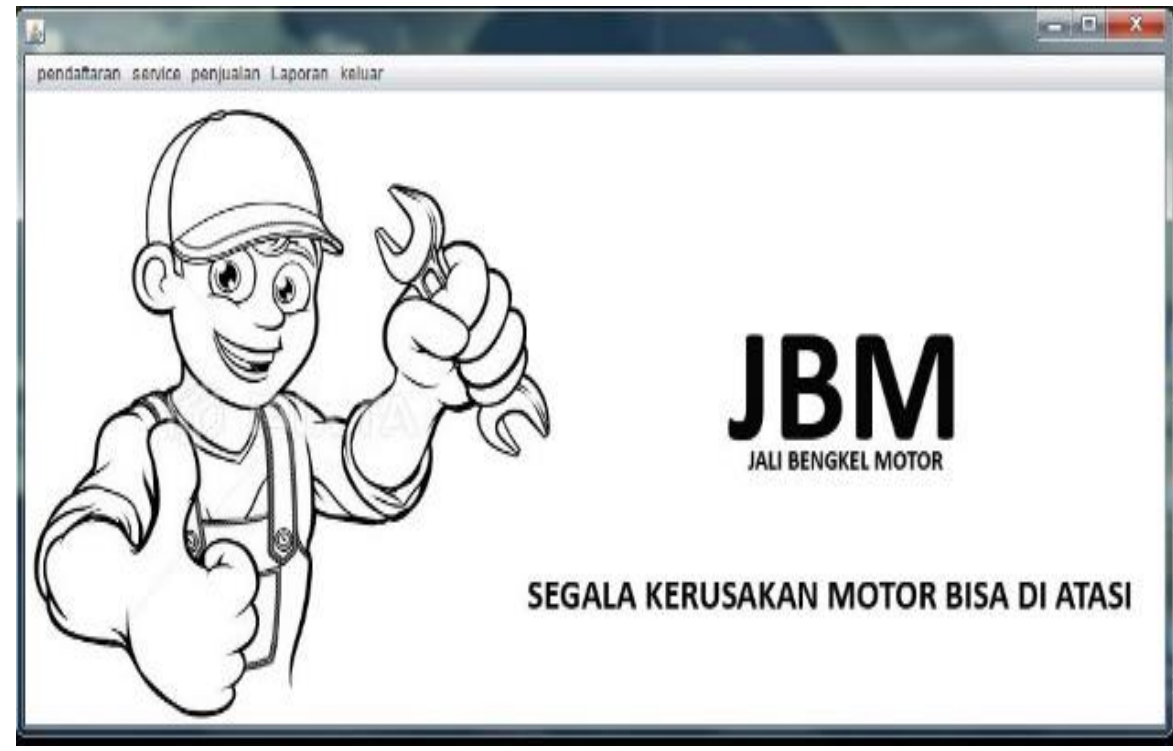

Gambar 2. Tampilan Menu Utama

Pada tampilan ini terdapat menu utama yang di gunakaan administrator untuk masuk kemenu salanjutnya yaitu pendaftaran, service, penjualan dan laporan 


\section{Tampilan Menu Pendaftaran}

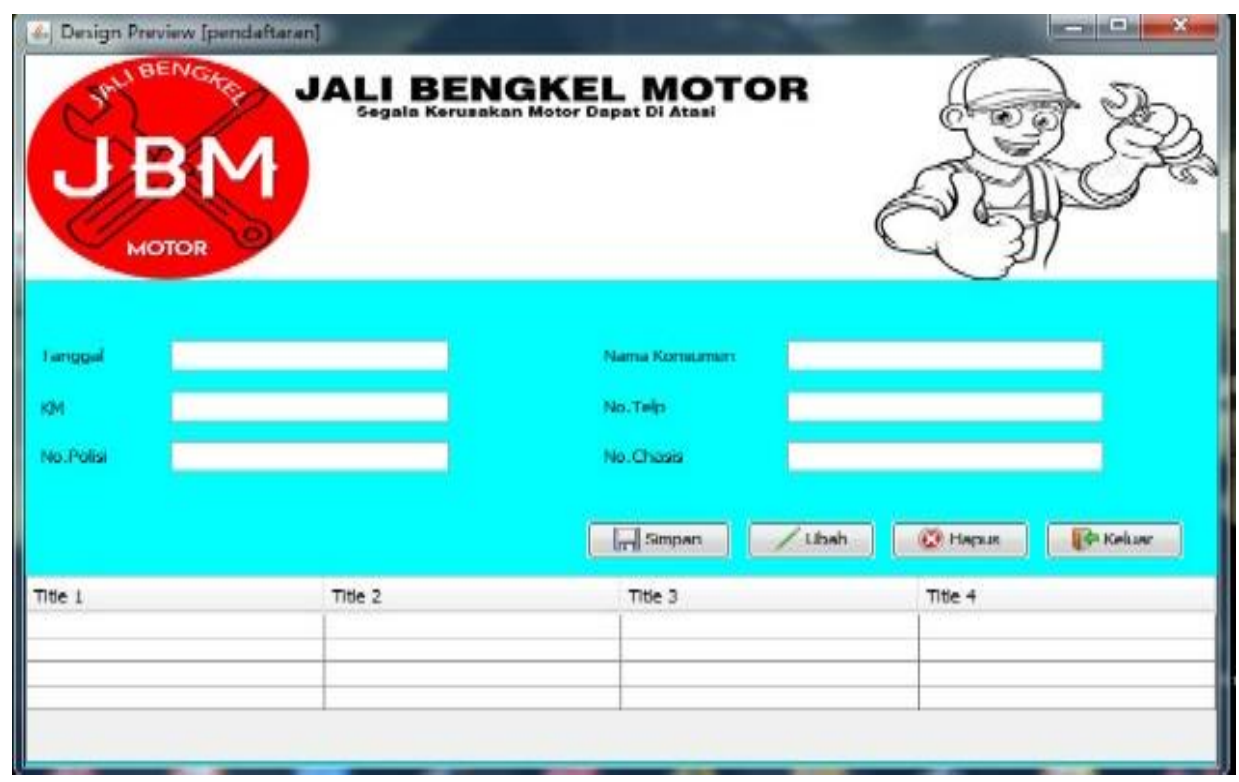

Gambar 3. Tampilan Menu Pendaftaran

Tampilan ini merupakan tampilan untuk melakukan update data user yang melakukan service kendaran bermotor.

\section{Tampilan Menu Service}

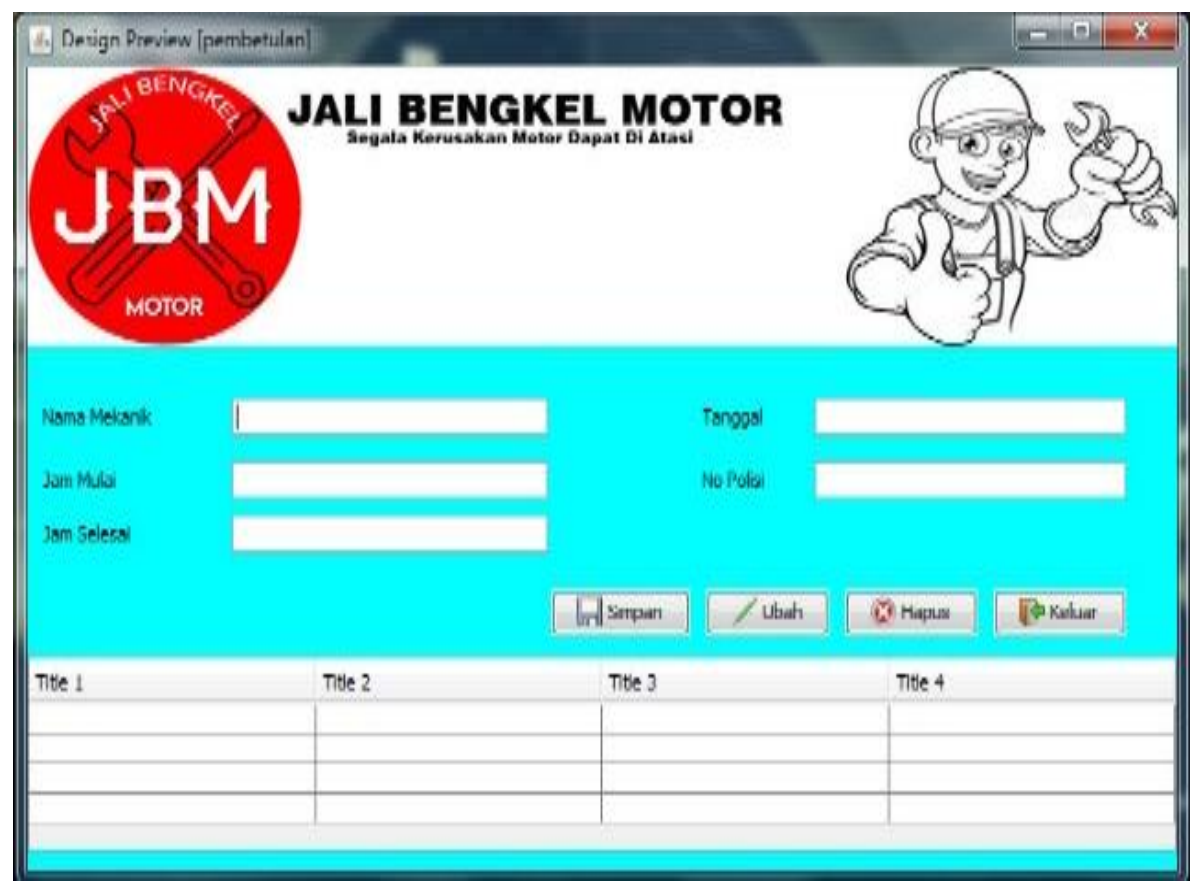

Gambar 4. Tampilan Menu Pembetulan

Pada tampilan menu ini administrator melakukan input motor yang ingin diservice dan juga nama mekanik yang mengerjakan service motor tersebut. 


\section{Tampilan Menu Penjualan Sapare Part}

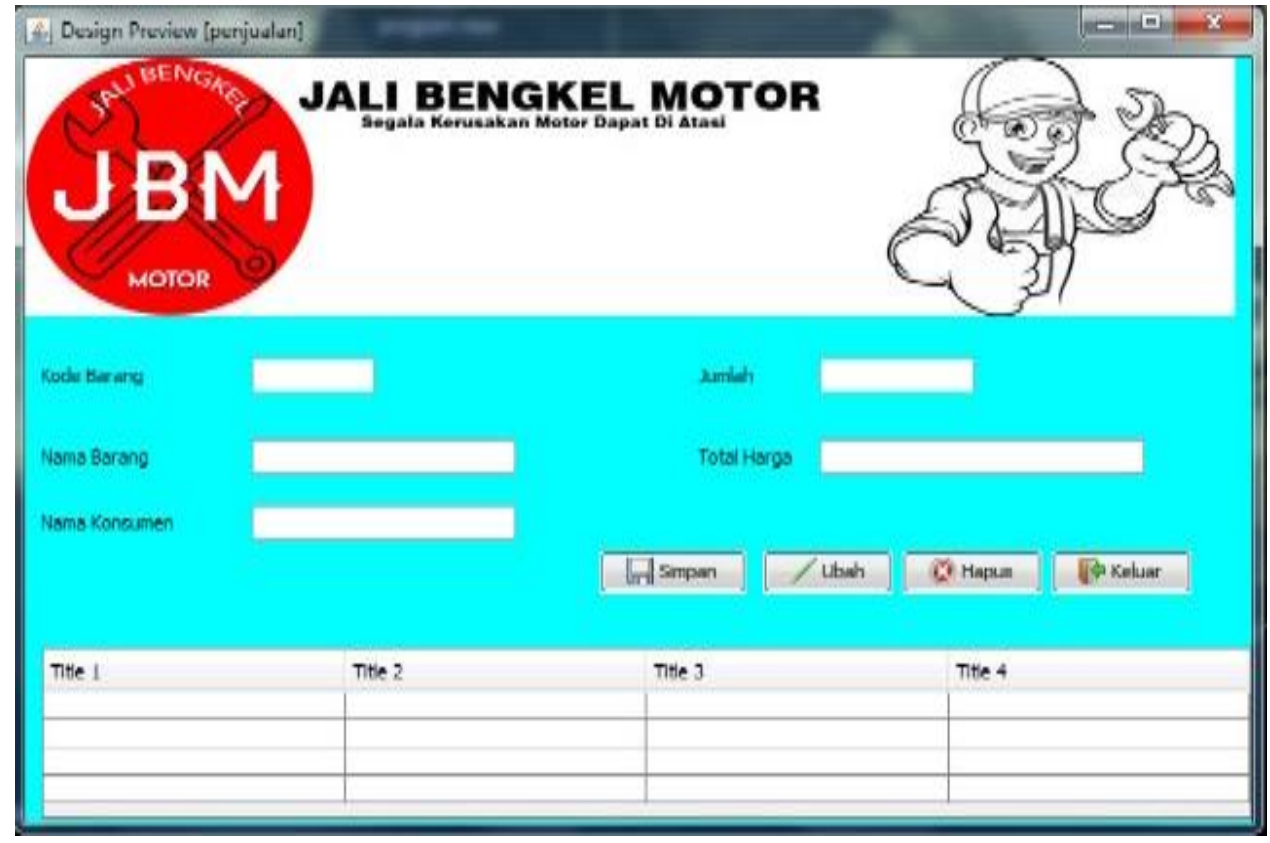

Gambar 5. Tampilan menu penjualan

Pada tampilan menu ini administrator melakukan input pembelian Spare Part yang dibutuhkan oleh costumer.

\section{Tampilan Menu Delivery Spare Part}

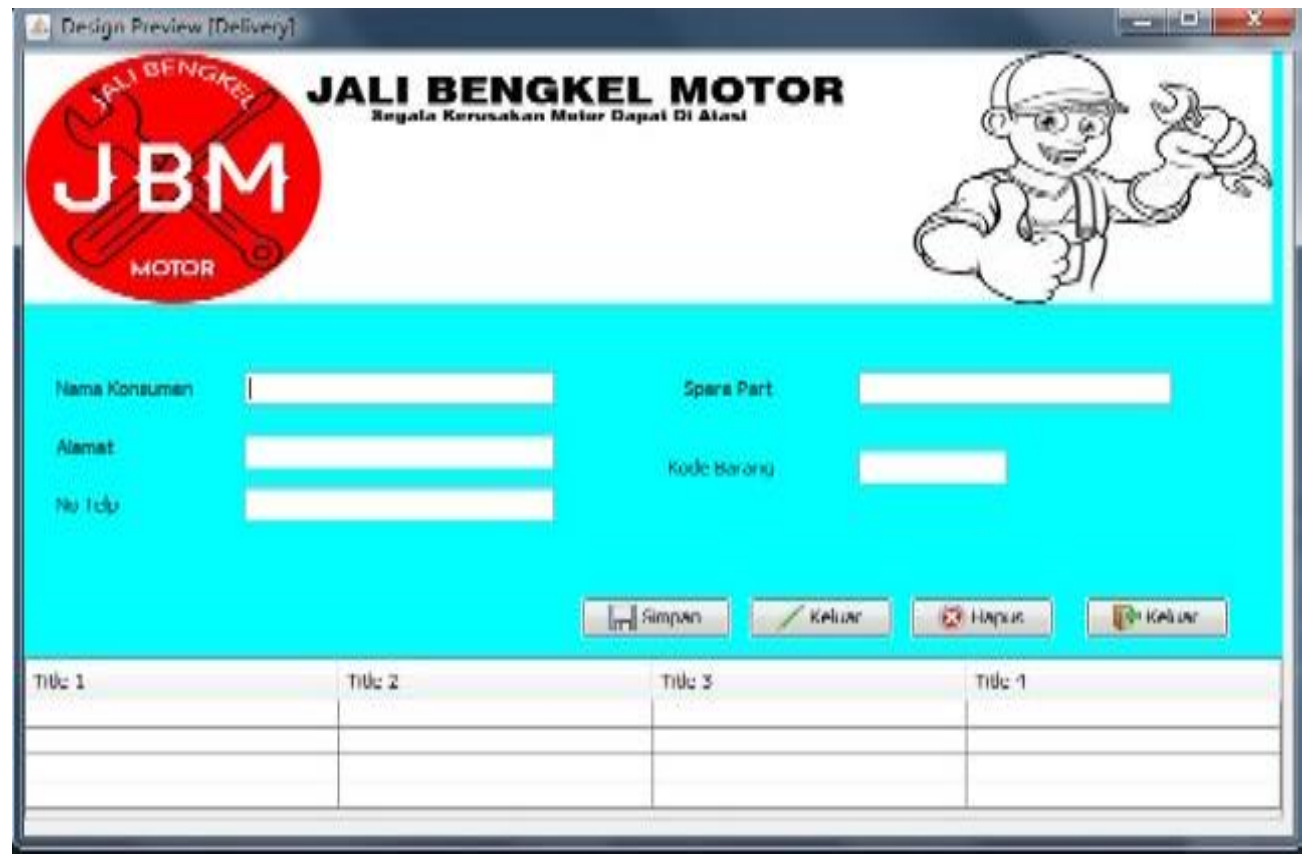

Gambar 6. Tampilan menu delivery

Pada tampilan menu ini administrator melakukan input pembelian Spare Part yang dibutuhkan oleh costumer dan mengantarkan pesanan yang diminta ketempat costumer yang memesan Spare Part.

\section{SIMPULAN}

Pada bab ini akan dibahas tentang kesimpulan yang berisi hasil-hasil yang diperoleh setelah dilakukan analisis perancangan dan implementasi dari perancangan perangkat lunak yang dibangun. Serta 
kepuasan pelanggan terhadap pelayanan merupakan salah satu tujuan utama perusahaan untuk meningkatkan efektifitas kinerja perusahaan dan meningkatkan sumber daya perusahaan. Pembuatan Sistem Aplikasi Pendaftaran Service Motor dan Penjualan Spare Part yang sistematis merupakan hal yang sangat membantu bagi pengelolaan keluhan pelanggan. Ketidak akuratan sistem yang terdahulu dapat dicegah dan dapat ditingkatkan kearah yang lebih baik dan keseluruhan datanya dapat dipertanggung jawabkan. Sistem Aplikasi Pendaftaran Service Motor dan Penjualan Spare Part ini akan dibangun secara sistematis dan tentunya terkomputerisasi sehingga layak digunakan, inovatif, informatif, dan akurat.

\section{DAFTAR PUSTAKA}

Barnabas, B. (2018). Grounded Research/Grounded Theory (Metode Penelitian Grounded. 3.

Erlangga, Rifal Surya. (2013). Sistem Informasi Pelayanan Jasa Service dan Penjualan SparePart Motor Berbasis Dekstop Pada Benkel Merdeka Abadi Motor Bandung.

Jogiyanto HM, M. (2005). Analisis dan Desain Sistem Informasi Pendekatan Terstruktur Teori dan Praktis Aplikasi Bisnis. Rasmawati, C. (2012). Aplikasi Penjualan Batako Pada Perusahaan Batako Kurnia Blok.

Sinambela. (2011). pengertian service. Sinabela, 5. 